Article

\title{
Evolutionary Game Research on Symmetry of Workers' Behavior in Coal Mine Enterprises
}

\author{
Kai Yu ${ }^{1}$, Lujie Zhou ${ }^{1,2, *}$, Qinggui Cao ${ }^{1, *}$ and Zhen $\mathrm{Li}^{1}$ \\ 1 College of Mining and Safety Engineering, Shandong University of Science and Technology, \\ Qingdao 266590, China; ykxfkd@163.com (K.Y.); yskdk@sina.com (Z.L.) \\ 2 State Key Laboratory of Mining Disaster Prevention and Control Co-founded by Shandong Province and the \\ Ministry of Science and Technology, Shandong University of Science and Technology, Qingdao 266590, China \\ * Correspondence: zhouqingdao@yeah.net (L.Z.); ykawyn@126.com (Q.C.); \\ Tel.: +86-1396-989-1661 (L.Z.); +86-1396-984-9358 (Q.C.)
}

Received: 4 January 2019; Accepted: 28 January 2019; Published: 31 January 2019

check for updates

\begin{abstract}
Statistics show that humans' unsafe behaviors are the main cause of accidents. Because of the asymmetry of game benefits between managers and coal miners, the stability of workers' behaviors is affected and unsafe behaviors are produced. In this paper, the symmetry of the behavior benefits of coal mine workers is studied, using game theory. In order to observe the dynamic game evolution process of behavioral stability, the paper establishes a system dynamics (SD) model and simulates it. The SD simulation results show that with the continuation of the game, when the benefits for safety managers and workers are asymmetric and the safety manager's safety inspection benefits are less than the non-inspection benefits, the manager may not conduct safety inspections, which poses a great hidden danger to safety production. Through dynamic incentives to regulate the symmetry of income of coal mine safety managers and coal mine workers, the purpose of enhancing the stability of safety behavior is achieved. The research results of the paper have been successfully applied to coal mine enterprises.
\end{abstract}

Keywords: benefits symmetry; behavioral stability; evolutionary game; system dynamics; dynamic incentive

\section{Introduction}

A large number of statistics show that in some large-scale accidental disasters, unsafe human behavior is the main cause of the accident [1-3]. More than $80 \%$ of coal mine accidents in China are directly or indirectly caused by unsafe human behaviors [4]. In safety production, the game income of coal mine managers and workers is asymmetric, which leads to unstable behavior on both sides. Therefore, it is very important to study the symmetry of game benefits and behavior stability between managers and workers in coal mine enterprises.

In terms of coal mine accidents, Chen et al. studied the development trend of coal mine accidents in China, and analyzed the human factors, indicating that the unsafe behavior of human beings is the main cause of the accidents [5]. Nouri assessed the safety of the Iranian Gas Company and concluded that workers' unsafe behavior is the main cause of accidents [6]. Ianole studied applied behavioral economics and its trends [7]. Experts have shown from a wide range of studies the importance of unsafe human behavior to safety production.

If safety behaviors are studied in depth, we must first understand their specific definition. In the late 1970s, Heinrich proposed that people's unsafe behavior and material insecurity led to accidents [8]. Based on Heinrich, Reason proposed a model of human factors in the 1990s and established an accident 
model, which was named "cheese". The theories presented that the potential risks in the system are deeply defended at all levels and ultimately lead to accidents [9].

Based on the definition of unsafe behavior, behavioral symmetry [10] and behavioral stability [11] were studied. In the construction industry, safety behaviors are studied from the aspects of safety cognition and safety climate. For example, Fang et al. established a cognitive model of unsafe behavior of construction workers [12]. Lyu et al. studied delay behavior from the aspects of safety climate and safety results [13]. Safety leadership has a great influence on the evolution of safety behaviors. For example, Beatriz et al. studied the influence of safety leadership on workers' safety behaviors in the light of working conditions [14], and Shen studied the transfer mechanism of safety behaviors [15].

In summary, most of the studies focus on the factors, formation mechanisms, and models of safety behaviors, while few focus on the dynamic evolution process of safety behaviors. Therefore, the paper uses dynamic evolutionary game theory to analyze the evolution process of safety behaviors.

Game theory has been widely used in many fields of scientific research. It discusses open research topics of importance to economics and the broader social sciences [16]. Game theory has been used to study the improvement of resources and environment. Zhao et al. analyzed environmental protection materials and environmental risks [17]. Using game theory, Feng et al. put forward the method of optimizing resource allocation [18]. In social science, Lu et al. established a multi-party evolutionary game model [19]. Sun et al. focused on the game between employer and worker mobility [20]. Wang et al. studied the interaction among government, enterprises, and workers [21].

Game theory has made outstanding contributions in social science and other research. Combining game theory with safety behaviors of coal miners provides a new research direction for studying the evolution process of them. If the game theory is used alone, the evolutionary results of safety behaviors in equilibrium state can be obtained, but the evolutionary state of safety behaviors in each time period cannot be observed better. Therefore, the paper combines game theory with system dynamics, gives full play to system dynamics, and deeply studies the changing state of workers' safety behaviors in each time period.

Professor Forrester (Jay W. Forrester) of the Massachusetts Institute of Technology (MIT) pioneered System Dynamics (SD) in 1956, which is combined qualitative analysis with quantitative analysis to study the functions of complex systems and the interaction of behaviors through model simulations [22,23]. In the construction industry, system dynamics is used to analyze the safety behaviors of workers, such as the feedback mechanism of workers' safety attitudes and safety behaviors [24], the influencing factors of workers' unsafe behaviors [25], and the influence of workers' work interference and family conflict on safety behaviors [26]. In enterprise management, system dynamics is used to simulate the relationship between safety investment and coal mine accidents [27], and optimize the risk management of chemical enterprises [28]. In other research fields, system dynamics is also used as a research tool to analyze the dependence between safety factors [29], and the safety psychological process of railway workers [30].

The behavior benefits matrix of the safety management department workers group is constructed to solve the problem of asymmetry of benefits and unstable behaviors between the safety management department and multiple workers groups. Based on the matrix, the evolutionary game analysis is carried out on the behavior stability of coal mine workers. The evolutionary game method is combined with system dynamics (SD), and Vensim is used to build the evolutionary SD model of safety behaviors. The dynamic evolution rules of the safety management department and the two coal mine workers groups are deeply analyzed through simulation by SD.

\section{Evolutionary Game Analysis}

Coal mining enterprises usually include frontline units and safety management departments. Workers are the main producers of behavior, which determine whether coal mining enterprises can operate safely. As an external factor, managers play a direct role in supervising the behaviors of workers, and will assume corresponding responsibilities. 
Under the inspection of safety managers, workers may follow safety instructions to take actions, or may not comply with instructions to choose risky operations [31-33]. Workers are affected by safety managers, but also affect the decision-making behavior of the managers. Therefore, it can be considered that there is a game relationship between the inspection of the safety management department and the behavior choice of coal mine workers, but in the actual production of coal mine enterprises, the safety management department is facing more than a group of workers. Therefore, the paper analyses the game between a safety management department and two groups of coal mine workers.

The relevant assumptions of the game are as follows:

(1) Limited rational game group: coal mine workers Group 1, coal mine workers Group 2, coal mine safety management department. The strategies of coal mine workers groups include "safe behavior" and "unsafe behavior". Safety management departments have "inspection" and "no inspection" strategies.

(2) It is assumed that managers and coal miners are rational economic persons who determine their behavior based on cost-benefit analysis. Coal mine workers do not consciously abide by safety operating rules at all times. Similarly, managers do not always carry out safety checks, but once they do, they will strictly abide by the rules and regulations. That is to say, if workers' unsafe behaviors are found, they will be punished according to safety management regulations [34-36].

(3) Coal mine safety management departments and coal miners have limited rational characteristics. That is, there will inevitably be errors in logical reasoning or decision-making judgment and self-interest considerations. The logical reasoning or decision-making judgment is illustrated by examples. Managers would spend a lot of time checking Group 1 if they thought that Group 1 often had unsafe behavior, while Group 1 thought that the manager would not carry out safety checks immediately after checking, so the safety consciousness of Group 1 began to slacken. Consideration of self-interest is illustrated by examples. Group 2 believes that inspectors will inspect Group 1, according to the usual practice. Unsafe behaviors occur repeatedly in a short period of time, while members of groups with high safety awareness choose conformity behaviors under group pressure. From a group perspective, this may move the coal miners far away from the optimal benefit decision-making choice.

(4) The $r$ is the reward for safety behaviors of coal mine workers. The $d$ is the cost of taking safe actions, such as the extra physical and time required to take safety behaviors. If unsafe behavior is taken, there is no need to pay the corresponding cost. On the contrary, this part of the benefit will be obtained. The $e$ is the additional benefits (such as psychological benefits, economic benefits, time benefits, etc.) for the coal miners who take unsafe behaviors. If the safety management department finds unsafe behaviors, it will take measures to correct unsafe behavior, such as education and training, and impose fines. The $F$ is a penalty for unsafe behaviors (mainly economic penalties). The $H$ is the loss that the group itself needs to bear, when the group has unsafe behaviors. The income obtained by the safety management department from inspecting the behaviors of coal miners mainly comes from the punishment $(F)$ for the unsafe behaviors of coal miners. The $C$ is the cost of safety inspection. The $D$ is the loss sustained by the coal mine safety management department when the coal mine workers take unsafe behaviors. The probability of workers Group 1 adopting unsafe behaviors is $x_{1}$, and that of Group 2 is $x_{2}$. The probability of safety management inspection is $a_{1}$.

The benefits matrix of Group 1 and Group 2 is shown in Table 1.

Table 1. The benefits matrix of Group 1 and Group 2.

\begin{tabular}{ccc}
\hline \multirow{2}{*}{ Benefits of Group 1 } & \multicolumn{2}{c}{ Benefits of Group 2 } \\
\cline { 2 - 3 } & Unsafe Behaviors $\left(\boldsymbol{x}_{\mathbf{2}}\right)$ & Safety Behaviors (1- $\left.\boldsymbol{x}_{\mathbf{2}}\right)$ \\
\hline Unsafe Behaviors $\left(x_{1}\right)$ & $\left(d_{1}-H_{1}-F_{1}-a_{1} \times F_{2}, d_{2}-H_{2}-F_{2}-a_{1} \times F_{1}\right)$ & $\left(d_{1}-H_{1}-F_{1}-a_{1} \times F_{2}, r_{2}-d_{2}\right)$ \\
Safety Behaviors $\left(1-x_{1}\right)$ & $\left(r_{1}-d_{1}, d_{2}-H_{2}-F_{2}-a_{1} \times F_{1}\right)$ & $\left(r_{1}-d_{1}, r_{2}-d_{2}\right)$ \\
\hline
\end{tabular}


Group 1 chooses the benefits of safe behaviors $v_{11}$ and the benefits of choosing unsafe behaviors $v_{12}$ as Equations (1) and (2).

$$
\begin{gathered}
v_{11}=\left(r_{1}-d_{1}\right) \times a_{1} \times x_{2}+\left(1-a_{1}\right) \times x_{2} \times\left(r_{1}-d_{1}\right)+\left(r_{1}-d_{1}\right) \times a_{1} \times\left(1-x_{2}\right)+\left(1-a_{1}\right) \times\left(1-x_{2}\right) \times\left(r_{1}-d_{1}\right) \\
v_{12}=a_{1} \times x_{2} \times\left(d_{1}-H_{1}-F_{1}-a_{1} \times F_{2}\right)+a_{1} \times\left(1-x_{2}\right) \times\left(d_{1}-H_{1}-F_{1}-a_{1} \times F_{2}\right) \\
+\left(1-a_{1}\right) \times x_{2} \times\left(d_{1}-H_{1}-F_{1}-a_{1} \times F_{2}\right)+\left(1-a_{1}\right) \times\left(1-x_{2}\right) \times\left(d_{1}-H_{1}-F_{1}-a_{1} \times F_{2}\right)
\end{gathered}
$$

Therefore, Group 1 chooses the average expected benefits of safe behaviors and unsafe behaviors as Equation (3).

$$
v_{1}=x_{1} \times v_{11}+\left(1-x_{1}\right) \times v_{12}
$$

The $\mathrm{d} x_{1} / \mathrm{d} t$ represents the rate of change of the proportion of safe behaviors of Group 1 with time, and the replication dynamics of Group 1's selected safe behaviors can be obtained.

$$
\mathrm{G}\left(x_{1}\right)=\mathrm{d} x_{1} / \mathrm{d} t=x_{1} \times\left(v_{11}-v_{1}\right)=x_{1} \times\left(1-x_{1}\right) \times\left(v_{11}-v_{12}\right)
$$

Group 2 chooses the benefits of safe behaviors $v_{21}$ and the benefits of choosing unsafe behaviors $v_{22}$ as Equations (5) and (6).

$$
\begin{gathered}
v_{21}=\left(r_{2}-d_{2}\right) \times a_{1} \times x_{1}+\left(1-a_{1}\right) \times x_{1} \times\left(r_{2}-d_{2}\right)+\left(r_{2}-d_{2}\right) \times a_{1} \times\left(1-x_{1}\right)+\left(1-\mathrm{a}_{1}\right) \times\left(1-x_{1}\right) \times\left(r_{2}-d_{2}\right) \\
v_{22}=a_{1} \times x_{1} \times\left(d_{2}-H_{2}-F_{2}-a_{1} \times F_{1}\right)+a_{1} \times\left(1-x_{1}\right) \times\left(d_{2}-H_{2}-F_{2}-a_{1} \times F_{1}\right) \\
+\left(1-a_{1}\right) \times x_{1} \times\left(d_{2}-H_{2}-F_{2}-a_{1} \times F_{1}\right)+\left(1-a_{1}\right) \times\left(1-x_{1}\right) \times\left(d_{2}-H_{2}-F_{2}-a_{1} \times F_{1}\right)
\end{gathered}
$$

Therefore, Group 2 chooses the average expected benefits of safe behaviors and unsafe behaviors as Equation (7).

$$
v_{2}=x_{2} \times v_{21}+\left(1-x_{2}\right) \times v_{22}
$$

The $\mathrm{d} x_{2} / \mathrm{d} t$ represents the rate of change of the proportion of safe behaviors of Group 2 with time, and the replication dynamics of Group 2 selected safe behaviors can be obtained.

$$
\mathrm{G}\left(x_{2}\right)=\mathrm{d} x_{2} / \mathrm{d} t=x_{2} \times\left(v_{21}-v_{2}\right)=x_{2} \times\left(1-x_{2}\right) \times\left(v_{21}-v_{22}\right)
$$

The safety management department randomly competes with any of the two groups, and the benefits matrix is shown in Table 2 .

Table 2. Benefits management matrix.

\begin{tabular}{ccc}
\hline \multirow{2}{*}{ Strategy Selection for Groups 1 and 2} & \multicolumn{2}{c}{ Safety Management Benefits } \\
\cline { 2 - 3 } & Safety Inspection $\left(\boldsymbol{a}_{\mathbf{1}}\right)$ & Safety Non-Inspection $\left(\mathbf{1}-\boldsymbol{a}_{\mathbf{1}}\right)$ \\
\hline Both groups choose unsafe behaviors & $F_{1}-D_{1}+F_{2}-D_{2}-C$ & $-D_{1}-D_{2}$ \\
Group 1 chooses Safety Behaviors; & $F_{2}-D_{2}-C$ & $-D_{1}$ \\
Group 2 chooses unsafe behaviors & & $-D_{2}$ \\
Group 2 chooses Safety Behaviors; & $F_{1}-D_{1}-C$ & 0 \\
Group 1 chooses unsafe behaviors & 0 & \\
Both groups choose safety behaviors & &
\end{tabular}

The benefits of safety managers' inspection and non-inspection are shown in Equations (9) and (10).

$$
\begin{gathered}
u_{1}=x_{2} \times\left(F_{2}-D_{2}\right)+x_{1} \times\left(F_{1}-D_{1}\right)-C \\
u_{2}=-x_{2} \times D_{2}-x_{1} \times D_{1}
\end{gathered}
$$


Therefore, the average expected benefits of safety managers' inspection and non-inspection are shown in Equation (11).

$$
u=a_{1} \times u_{1}+\left(1-a_{1}\right) \times u_{2}
$$

The $\mathrm{d} u / \mathrm{d} t$ is used to represent the change rate of the proportion of safety inspection with time, and the replication dynamics of safety inspection can be obtained.

$$
\mathrm{G}(u)=\mathrm{d} u / \mathrm{d} t=a_{1} \times\left(u_{1}-u\right)=a_{1} \times\left(1-a_{1}\right) \times\left(u_{1}-u_{2}\right)
$$

\section{Model Simulation Analysis}

\subsection{System Dynamics (SD) Simulation Model}

Safety management departments in coal mine enterprises face more than one workers group. Based on game theory, the paper establishes a system dynamics model of game between managers and multiple workers groups, as shown in Figure 1.

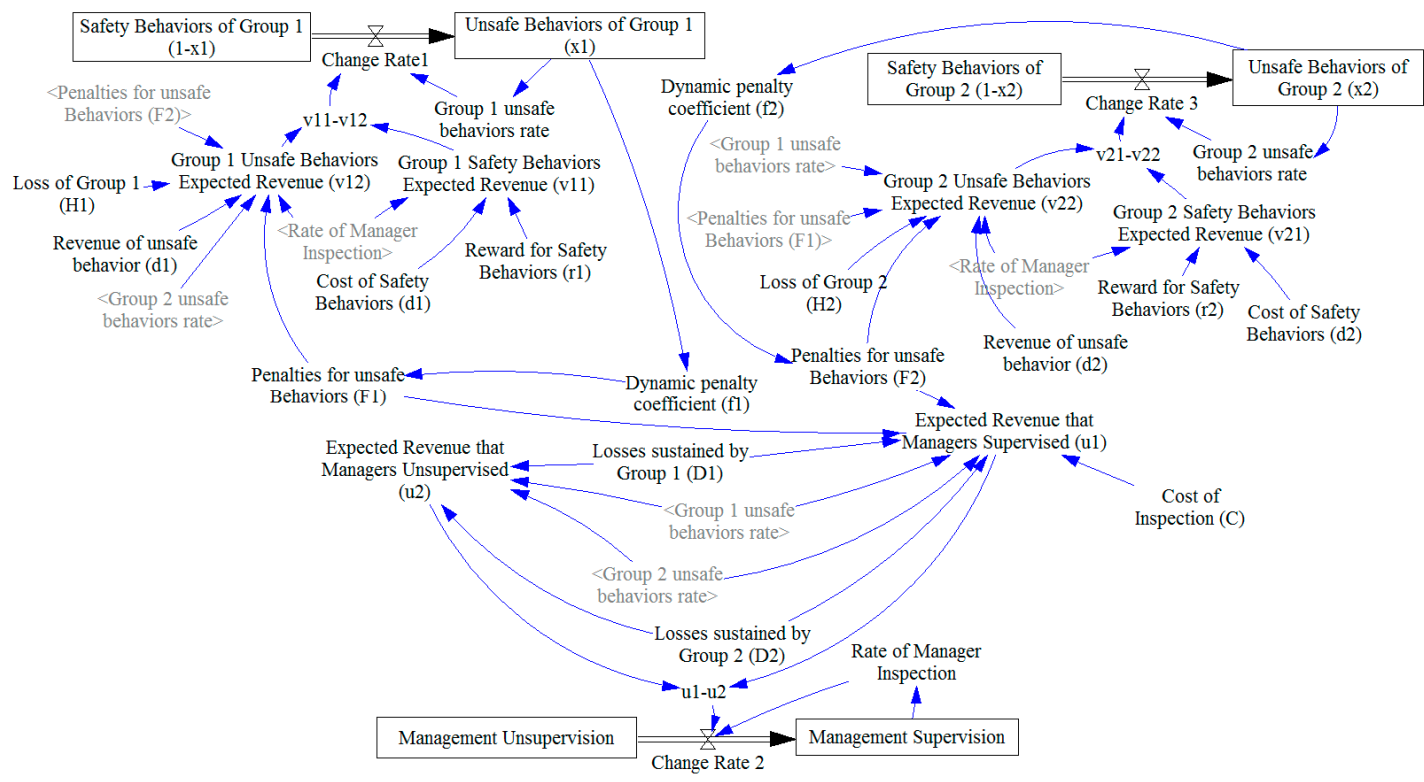

Figure 1. System dynamics (SD) model of evolutionary game.

The SD model of the evolutionary game has six state variables, three rate variables, 12 auxiliary variables, and 11 environmental variables. The system dynamics equation in the SD model is determined by the replication dynamic equation in the evolutionary game model.

\subsection{Strategies Simulation Analysis}

According to the above variables settings, the system dynamics model is analyzed by Vensim software (PLE, Ventana Systems. Inc, Harvard, MA., USA). The simulation results are shown in Figures $2-4$. 


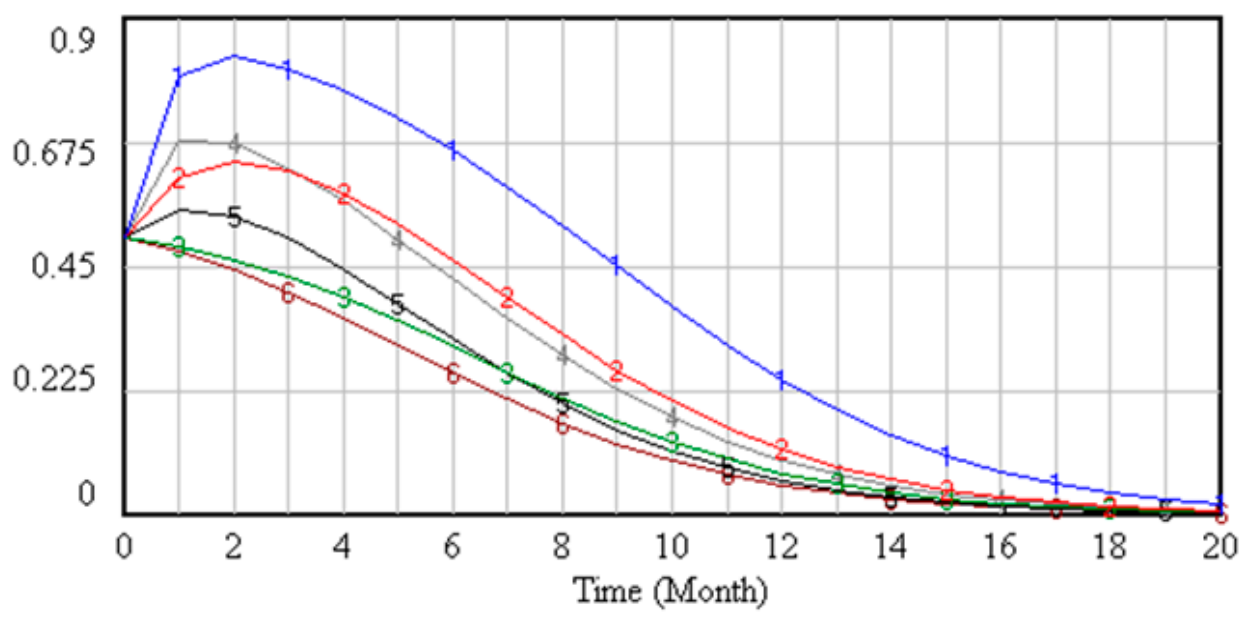

Figure 2. The probability of manager safety inspection under general state and dynamic penalty.

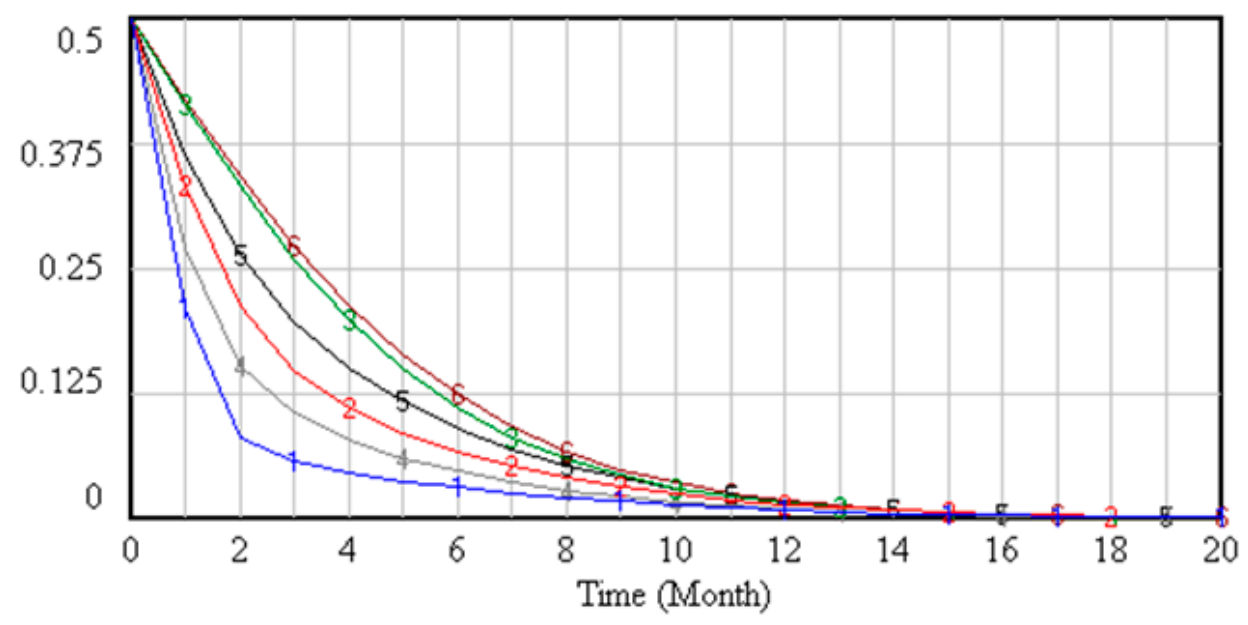

Figure 3. The probability of Group 1 choosing unsafe behaviors under general state and dynamic penalty.

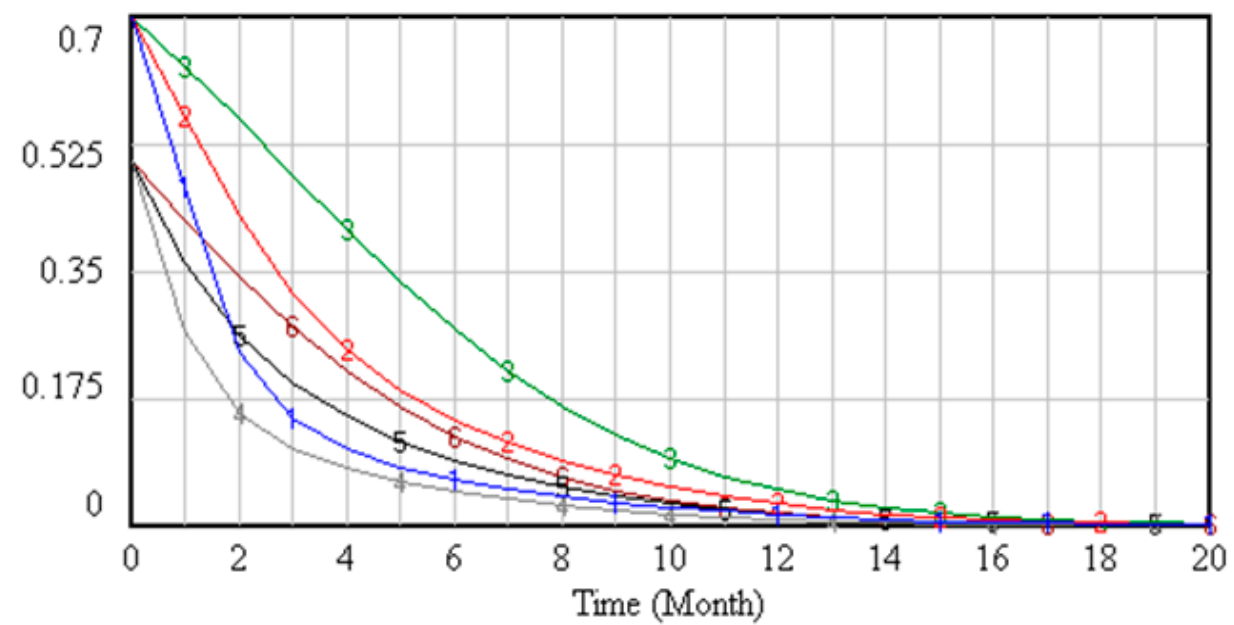

Figure 4. The probability of Group 2 choosing unsafe behaviors under general state and dynamic penalty.

In Figures 2-4, curves 1, 2, 4, and 5 show the dynamic evolution of strategies of each player when managers choose dynamic penalties. Curves 3 and 6 are the dynamic evolution of each player's strategy, when the probability of safety inspection is $50 \%$ and the unsafe actor is punished generally. 
Curve 3 is the dynamic evolution of each player's strategy, when the level of unsafe behavior of both groups is $50 \%$, the level of unsafe behavior of another group is $70 \%$. Curve 6 is the dynamic evolution of the strategies of each player when the level of unsafe behaviors of two groups is $50 \%$. Contrast curves 3 and 6 show that the level of unsafe behaviors of coal miners has an effect on the safety inspection of managers, while the level of unsafe behaviors of group 2 has little effect on the level of unsafe behaviors of group 1. Curves 3 and 6 in Figure 2 show that with the continuation of the game, asymmetry of the benefits between safety managers and workers began to appear. The level of group unsafe behaviors decreases, and the source of benefits for safety managers is 0 . The safety manager chooses the safety probability not to rise but to fall. This will cause a great potential safety hazard to coal mining enterprises, which is not in line with the actual situation.

Curves 1 and 4, 2 and 5, and 3 and 6 show that when the punishment is positively correlated with the level of unsafe behavior, the greater the correlation coefficient is, the faster the level of unsafe behavior decreases, and the shorter the time it takes for the final group to choose safe behaviors. When the level of unsafe behaviors of two groups of coal miners is different, the two sides also influence each other, and the effect is obvious. This is because the level of safety behaviors of both sides has an impact on the behaviors of safety managers, and the punishment of the groups is also related to the level of unsafe behaviors of the other group.

Part of the benefit from coal mine management comes from fines for unsafe behaviors. Therefore, in order to maximize profits, safety management departments tend to choose safety inspection as their initial strategy. The higher the level of group unsafe behavior is, the more likely managers will choose safety management. With the improvement of the level of group safety behaviors, the benefit of the coal mine safety management department decreases. When the benefit of inspection is less than that of non-inspection, the probability of inspection decreases and finally evolves into a hidden danger state.

Therefore, only considering dynamic punishment can reduce the level of group unsafe behavior to a certain extent, but it can't motivate safety managers to carry out safety inspection continuously. This should consider how to adjust the benefit symmetry of managers and workers. In order to stimulate safety managers to conduct continuous safety inspections, dynamic incentives are considered here. The magnitude of dynamic incentive coefficient is negatively correlated with the level of group unsafe behaviors, that is, the greater the level of group safe behaviors, the greater the incentive of coal mine enterprises to the coal mine safety management department, and the greater the incentive to the group. The SD model with dynamic incentives is shown in Figure 5, and the simulation results are shown in Figures 6-8.

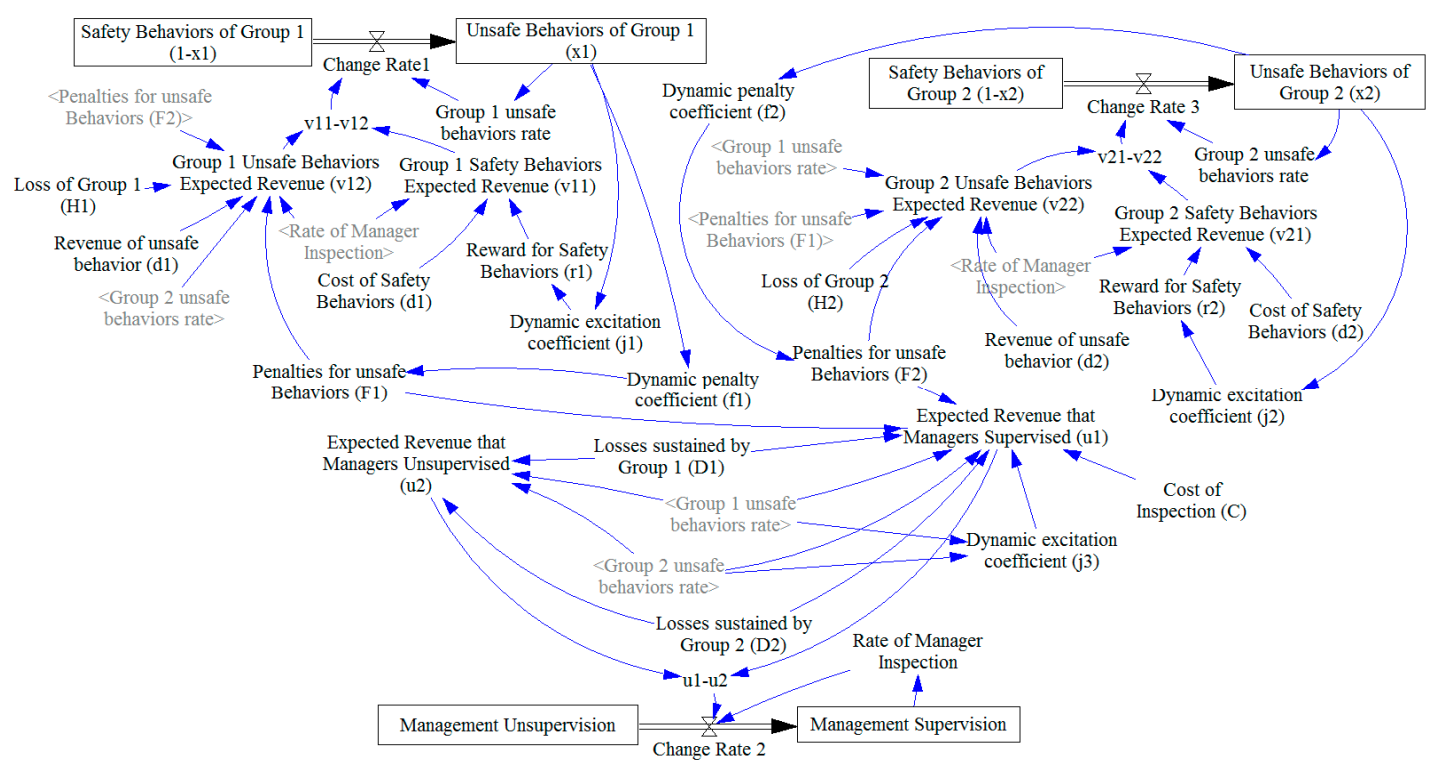

Figure 5. SD model with dynamic incentives. 


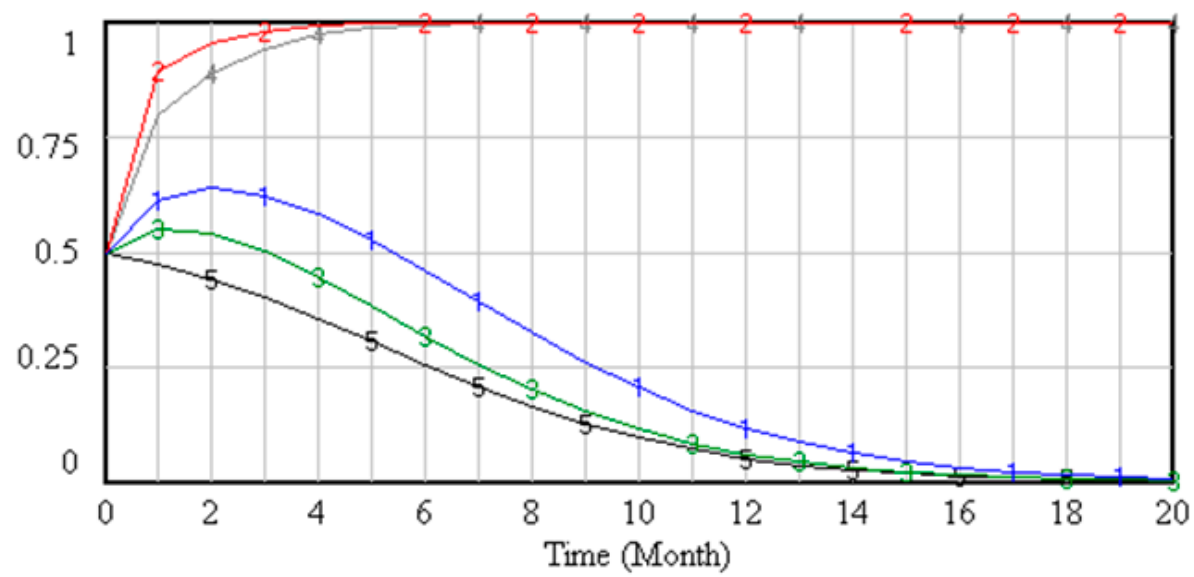

Figure 6. The probability of managers choosing safety inspection with dynamic incentives.

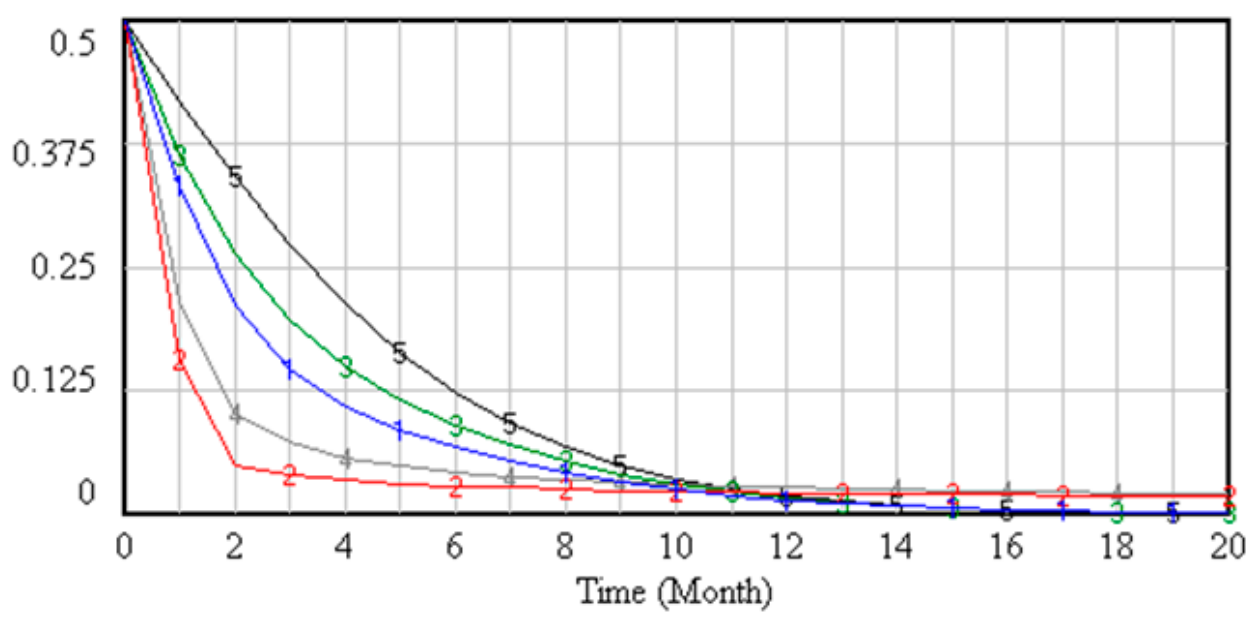

Figure 7. The probability of Group 1 choosing unsafe behaviors with dynamic incentives.

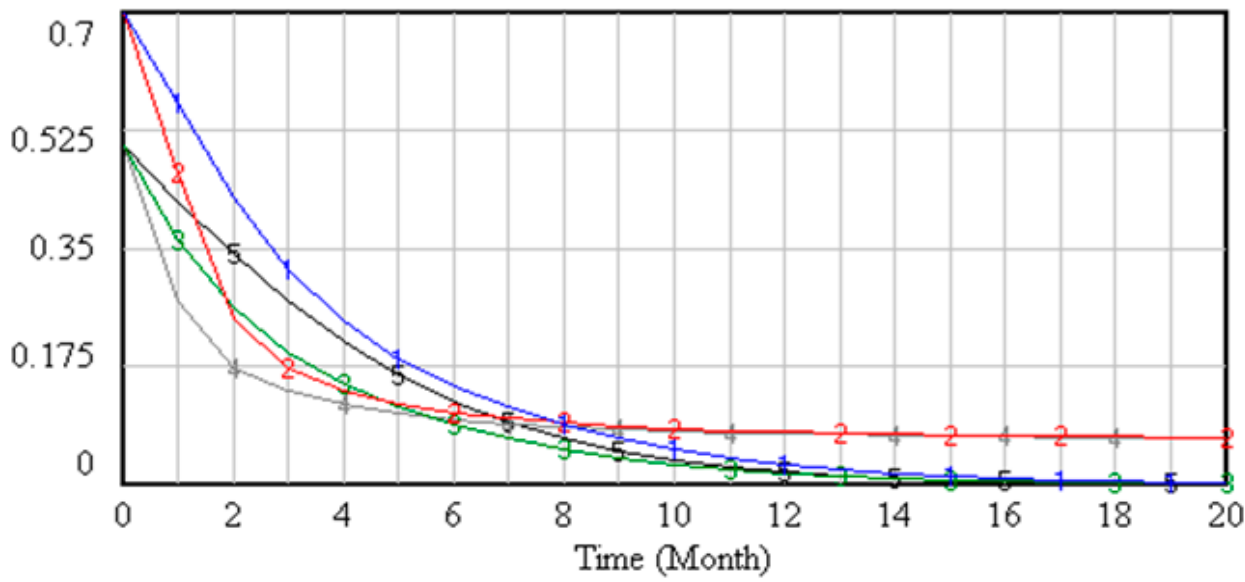

Figure 8. The probability of Group 2 choosing unsafe behaviors with dynamic incentives.

From the curves 2 and 4 of Figure 6, it can be seen that introducing dynamic incentives can improve the symmetry of game benefits between managers and workers. At the same time, it can also motivate safety managers to carry out safety inspections continuously and ensure the stability of the safe operation of coal mine workers. It can also be seen that when the level of unsafe behavior of two groups is not the same, the lower the level of unsafe behavior of the groups, the more quickly safety managers can make a safety inspection. 
It can be seen from Figures 7 and 8 that after with the dynamic incentives, part of the benefits of coal mine workers depend on the level of safety behaviors of the groups. Therefore, the order of the decline rate of unsafe behavior level is: Dynamic incentive $>$ Dynamic punishment $>$ General punishment.

It is concluded from the simulation analysis that the dynamic incentives have a good effect on improving the benefit symmetry and behavior stability of managers and workers, and can promote the continuous supervision of safety managers and reduce the level of unsafe behavior of coal miners. Therefore, in the process of safety production, coal mine enterprises should give reasonable rewards and punishments to safety managers and workers to regulate the benefit symmetry of managers and workers and encourage them to choose safety behaviors, so as to ensure the smooth progress of safety production.

\section{Example Application}

Through the game analysis and SD simulation analysis of the safety management department and workers groups, it can be seen that dynamic incentives play a positive role in the stability of safety behaviors. Under the guidance of the theory, the Tangkou Coal Industry has been investigated on the spot. The existing violation treatment system has been optimized, the main content of which is to introduce a dynamic incentive system. Figure 9 shows the trend of violations of regulations in the Machinery and Electricity Team of Tangkou Coal Industry from January 2017 to November 2018. The team began to implement the dynamic incentive system in November 2017.

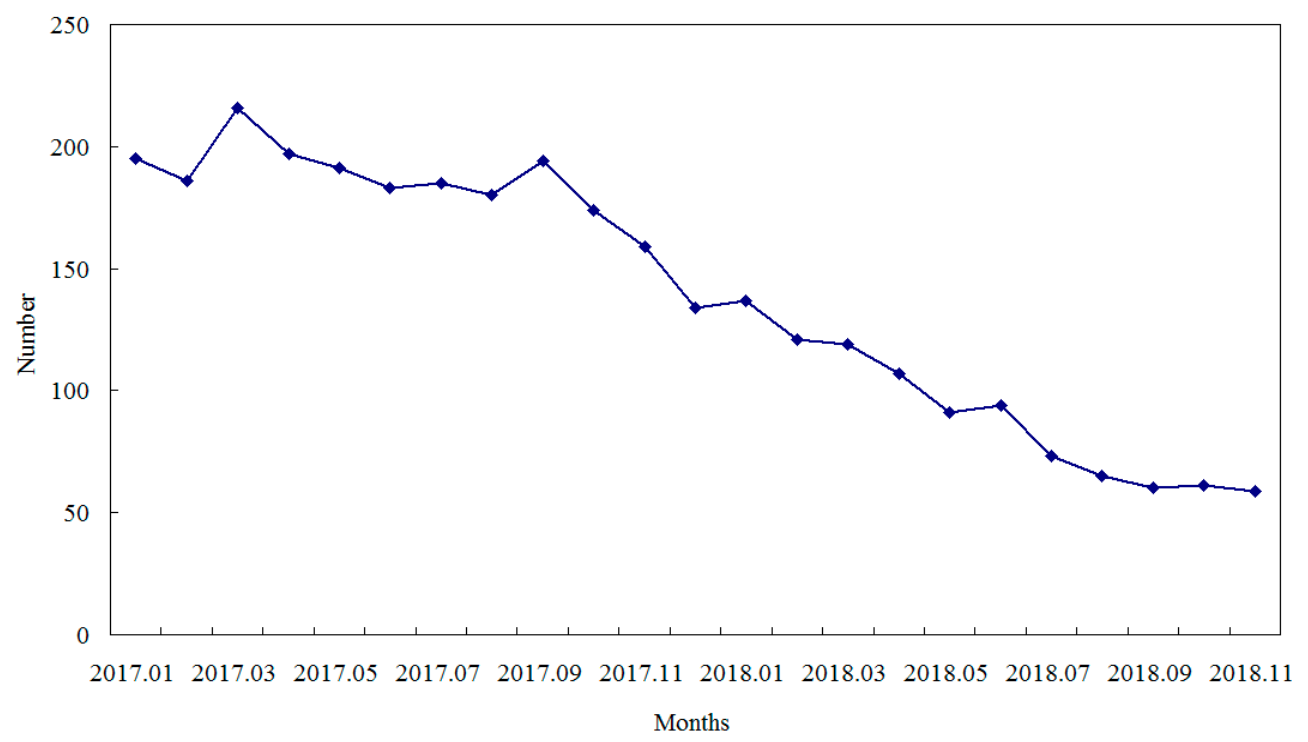

Figure 9. The trend of violations of regulations in the Machinery and Electricity Team from January 2017 to November 2018.

As can be seen from Figure 9, before the implementation of the dynamic incentive system (January 2017-October 2017), the number of violations of the team has been between 170-220. However, starting from November 2017, after the implementation of the dynamic incentive system, the number of violations of the team dropped rapidly. The number of violations dropped to below 70 in August 2018. The number of violations was stable at around 60 in September 2018, October 2018, and November 2018.

This paper compares and analyzes the violations of the team in the same month in 2017 and 2018, in order to more clearly analyze the changes in violations before and after the implementation of the dynamic incentive system, as shown in Figure 10. It can be clearly seen from Figure 10 that after the dynamic incentive measures were adopted, the number of violations of the team decreased significantly during the same period. 


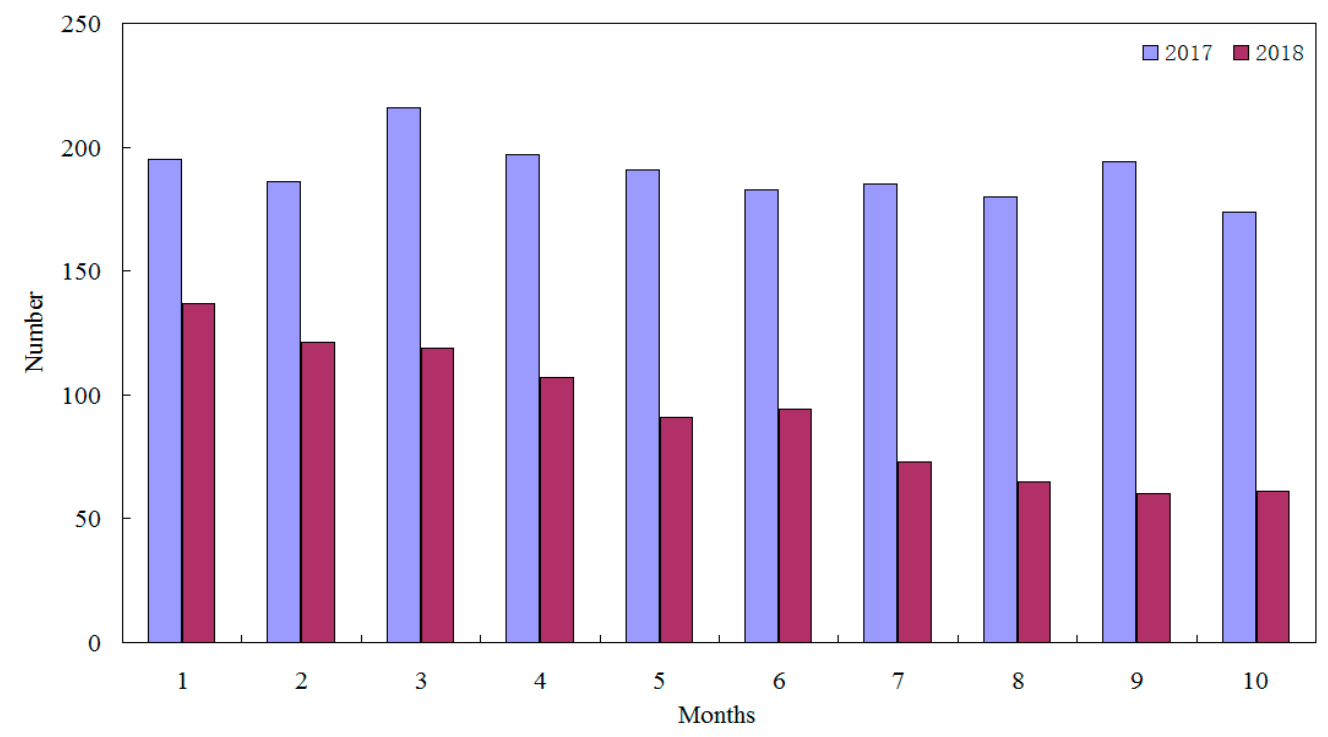

Figure 10. Comparison of the violations of the team in 2017 and 2018.

This shows that after the dynamic incentive measures, the safety management departments are motivated to be more active in the regulation of violations. At the same time, under the dynamic incentive measures, workers can also get extra benefits from safety production in the process of work, and their safety awareness is also improved.

It can be seen from Figures 9 and 10 that although the number of violations of the team has been significantly reduced, it is still around 60. This shows that there is still room for decline in the team's violations. Combined with the actual situation of Tangkou Coal Industry, if the dynamic incentive system can continue to be properly adjusted, the number of violations of the team may continue to decline. This is also the focus of the next research work in the paper.

\section{Conclusions}

The paper studies the symmetry of game benefits and behavior stability between coal mine safety managers and two groups of coal mine workers. Through the SD model, the evolutionary game process between safety management department and two groups of coal miners is analyzed in detail. The main conclusions are as follows:

(1) The symmetry of game benefits between safety managers and workers is analyzed, and their benefit matrix and game model is established.

(2) On the basis of the benefit matrix and game model, the SD model is constructed. The evolutionary process of game between the safety management department and two workers groups is analyzed in detail. The research shows that general punishment and dynamic punishment have a certain effect on reducing the safety behavior of coal miners, but at the same time, they also have some hidden dangers. Because the main source of benefit of coal mine safety managers is the fines for unsafe behavior, when the benefit symmetry is broken and the benefits of the safety management department's safety inspection is less than that of non-inspection, the safety management department ultimately does not carry out the safety inspection, which can be a great hidden danger to coal mine safety production.

(3) The dynamic incentive system is added to the SD model. It is concluded from the simulation analysis of the SD model that dynamic incentives can effectively regulate benefit symmetry and behavior stability of managers and workers, and promote continuous inspection by safety managers and reduce the level of unsafe behavior of coal mine workers.

(4) The research results of this paper have been applied to coal mine enterprises. By introducing dynamic incentive system, the existing reward and punishment system of enterprises has been adjusted and optimized. It effectively reduces the number of violations in coal mine enterprises. 
The simulation analysis and practical application in this paper show that the establishment of a reasonable dynamic incentive mechanism can effectively improve the safety level of coal mine enterprises in the process of safety production.

Author Contributions: Conceptualization, K.Y. and Z.L.; methodology, K.Y. and L.Z.; validation, K.Y., L.Z., and Q.C.; investigation, K.Y., L.Z., and Q.C.; data curation, L.Z.; writing-original draft preparation, K.Y.; writing-review and editing, L.Z. and Q.C.; visualization, K.Y. and Z.L.; supervision, L.Z. and Q.C.; project administration, L.Z. and Q.C.; funding acquisition, L.Z. and Q.C.

Funding: This research was funded by National Natural Science Foundation of China, grant number 51474138; 51574157; 51804180.

Acknowledgments: The authors would like to thank the National Natural Science Foundation of China and the authors of the references.

Conflicts of Interest: The authors declare no conflict of interest.

\section{References}

1. Choudhry, R.M.; Fang, D. Why operatives engage in unsafe work behavior: Investigating factors on construction sites. Saf. Sci. 2008, 46, 566-584. [CrossRef]

2. Abdelhamid, T.S.; Everett, J.G. Identifying root causes of construction accidents. J. Constr. Eng. Manag. 2000, 126, 52-60. [CrossRef]

3. Shappell, S.A.; Wiegmann, D.A. A human error approach to accident investigation: The taxonomy of unsafe operations. Int. J. Aviat. Psychol. 1997, 7, 269-291. [CrossRef]

4. China Administration of Work Safety. [EB/OL]. 2017. Available online: http://www.chinasafety.gov.cn/ newpage/ (accessed on 11 March 2017).

5. Chen, H.; Qi, H.; Long, R.; Zhang, M. Research on 10-year tendency of China coal mine accidents and the characteristics of human factors. Saf. Sci. 2012, 50, 745-750. [CrossRef]

6. Nouri, J.; Azadeh, A.; Mohammad, F.I. The evaluation of safety behaviors in a gas treatment company in Iran. J. Loss Prev. Process Ind. 2008, 21, 319-325. [CrossRef]

7. Ianole, R. Applied Behavioral Economics Research and Trends; IGI Global: Hershey, PA, USA, 2017; pp. 1-255.

8. Heinrich, H.W. Industrial Accident Prevention; McGraw-Hill: New York, NY, USA, 1979; pp. 19-26.

9. Reason, J. A systems approach to organizational error. Ergonomics 1995, 8, 1708-1721. [CrossRef]

10. Ahmed, R.R.; Channar, Z.A.; Soomro, R.H.; Vveinhardt, J.; Streimikiene, D.; Parmar, V. Antecedents of Symmetry in Physicians' Prescription Behavior: Evidence from SEM-Based Multivariate Approach. Symmetry 2018, 10, 721. [CrossRef]

11. Pertoldi, C.; Bahrndorff, S.; Kurbalija, N.Z.; Duun, R.P. The Novel Concept of "Behavioural Instability" and Its Potential Applications. Symmetry 2016, 8, 135. [CrossRef]

12. Fang, D.; Zhao, C.; Zhang, M. A Cognitive Model of Construction Workers' Unsafe Behaviors. J. Constr. Eng. Manag. 2016, 142. [CrossRef]

13. Lyu, S.; Hon, C.K.; Chan, A.P.; Wong, F.K.; Javed, A.A. Relationships among Safety Climate, Safety Behavior, and Safety Outcomes for Ethnic Minority Construction Workers. Int. J. Environ. Res. Public Health 2018, 15, 484. [CrossRef]

14. Fernández-Muñiz, B.; Montes-Peón, J.M.; Vázquez-Ordás, C.J. The role of safety leadership and working conditions in safety performance in process industries. J. Loss Prev. Process Ind. 2017, 50, 403-415. [CrossRef]

15. Shen, Y.; Ju, C.; Koh, T.Y.; Rowlinson, S.; Bridge, A.J. The Impact of Transformational Leadership on Safety Climate and Individual Safety Behavior on Construction Sites. Int. J. Environ. Res. Public Health 2017, 14, 45. [CrossRef] [PubMed]

16. Newton, J. Evolutionary Game Theory: A Renaissance. Games 2018, 9, 31. [CrossRef]

17. Zhao, R.; Neighbour, G.; Han, J.; McGuire, M.; Deutz, P. Using game theory to describe strategy selection for environmental risk and carbon emissions reduction in the green supply chain. J. Loss Prev. Process Ind. 2012, 25, 927-936. [CrossRef]

18. Feng, Q.; Cai, H.; Chen, Z.; Zhao, X.; Chen, Y. Using game theory to optimize allocation of defensive resources to protect multiple chemical facilities in a city against terrorist attacks. J. Loss Prev. Process Ind. 2016, 43, 614-628. [CrossRef] 
19. Lu, R.; Wang, X.; Yu, H. Multiparty Evolutionary Game Model in Coal Mine Safety Management and Its Application. Complexity 2018, 2018, 9620142. [CrossRef]

20. Sun, J.; Wang, X.; Shen, L. Research on the mobility behaviour of Chinese construction workers based on evolutionary gametheory. Econ. Res.-Ekon. Istraz. 2018, 31, 1-14.

21. Wang, Q.; Mei, Q.; Liu, S. Analysis of Managing Safety in Small Enterprises: Dual-Effects of Employee Prosocial Safety Behavior and Government Inspection. Biomed Res. Int. 2018, 2018, 6482507. [CrossRef]

22. Zhong, Y. System Dynamics; Science Press: Beijing, China, 2009; pp. 14-19.

23. Wang, Q. System Dynamics; Science Press: Beijing, China, 2009; pp. 25-33.

24. Shin, M.; Lee, H.-S.; Park, M. A system dynamics approach for modeling construction workers' safety attitudes and behaviors. Accid. Anal. Prev. 2014, 68, 95-105. [CrossRef]

25. Bouloiz, H.; Garbolino, E.; Tkiouat, M. A system dynamics model for behavioral analysis of safety conditions in a chemical storage unit. Saf. Sci. 2013, 58, 32-40. [CrossRef]

26. Wu, G.; Duan, K.; Zuo, J. System Dynamics Model and Simulation of Employee Work-Family Conflict in the Construction Industry. Int. J. Environ. Res. Public Health 2016, 13, 1059. [CrossRef] [PubMed]

27. Tong, L.; Dou, Y. Simulation study of coal mine safety investment based on system dynamics. Int. J. Min. Sci. Technol. 2014, 24, 201-205. [CrossRef]

28. Zhang, M.; Wang, X.; Mannan, M.S.; Qian, C.; Wang, J. A system dynamics model for risk perception of lay people in communication regarding risk of chemical incident. J. Loss Prev. Process Ind. 2017, 50, 101-111. [CrossRef]

29. Jiang, Z.; Fang, D.; Zhang, M. Understanding the Causation of Construction Workers' Unsafe Behaviors Based on System Dynamics Modeling. J. Manag. Eng. 2015, 31, 04014099. [CrossRef]

30. Da, X.; Zheng, W. A system dynamics model for railway workers' safety behaviors. In Proceedings of the 2016 IEEE International Conference on Intelligent Rail Transportation (ICIRT), Birmingham, UK, 23-25 August 2016; pp. 409-417.

31. Holovatch, Y.; Janke, W.; Thurner, S. Self-organization and collective behaviour in complex systems. Condens. Matter Phys. 2014, 17, 30001. [CrossRef]

32. Stephen, P.R. Organizational Behavior; Prentice Hall [Imprint]; Pearson Education, Limited: London, UK, 2010; pp. 17-32.

33. Hu, B. The Principle and Application of Qualitative Simulation of Group Behavior; Huazhong University of Science and Technology Press: Wuhan, China, 2006; pp. 27-39.

34. Yu, K.; Cao, Q.; Zhou, L. Study on qualitative simulation technology of group safety behaviors and the related software platform. Comput. Ind. Eng. 2019, 127C, 1037-1055. [CrossRef]

35. Cao, Q.; Yu, K.; Zhou, L.; Wang, L.; Li, C. In-depth research on qualitative simulation of coal miners' group safety behaviors. Saf. Sci. 2019, 113C, 210-232. [CrossRef]

36. Brocher, T. Orientation on group dynamics. Psychiatr. Commun. 1970, 13, 3-12. 